\title{
Successful C1 inhibitor short-term prophylaxis during redo mitral valve replacement in a patient with hereditary angioedema
}

\author{
Jonathan A Bernstein ${ }^{1 * \dagger}$, Suzanne Coleman ${ }^{2 \dagger}$, Arturo J Bonnin ${ }^{3 \dagger}$
}

\begin{abstract}
Hereditary angioedema is characterized by sudden episodes of nonpitting edema that cause discomfort and pain. Typically the extremities, genitalia, trunk, gastrointestinal tract, face, and larynx are affected by attacks of swelling. Laryngeal swelling carries significant risk for asphyxiation. The disease results from mutations in the C1 esterase inhibitor gene that cause $\mathrm{C} 1$ esterase inhibitor deficiency. Attacks of hereditary angioedema result from contact, complement, and fibrinolytic plasma cascade activation, where $\mathrm{C} 1$ esterase inhibitor irreversibly binds substrates. Patients with hereditary angioedema cannot replenish $\mathrm{C} 1$ esterase inhibitor levels on pace with its binding. When C1 esterase inhibitor is depleted in these patients, vasoactive plasma cascade products cause swelling attacks. Trauma is a known trigger for hereditary angioedema attacks, and patients have been denied surgical procedures because of this risk. However, uncomplicated surgeries have been reported. Appropriate prophylaxis can reduce peri-operative morbidity in these patients, despite proteolytic cascade and complement activation during surgical trauma. We report a case of successful short-term prophylaxis with C1 esterase inhibitor in a 51-year-old man with hereditary angioedema who underwent redo mitral valve reconstructive surgery.
\end{abstract}

\section{Background}

Attacks of hereditary angioedema (HAE) are characterized by sudden episodes of brawny, nonpitting edema, causing discomfort and pain [1]. Areas of the body typically affected include the extremities, genitalia, trunk, gastrointestinal tract, face, and larynx. Untreated patients with HAE are at risk for deadly attacks of laryngeal swelling, where up to $30 \%$ may asphyxiate [2].

HAE is an inherited autosomal dominant disorder resulting from any number of mutations in the $\mathrm{C} 1$ esterase inhibitor $(\mathrm{C} 1 \mathrm{INH})$ gene that cause $\mathrm{C} 1 \mathrm{INH}$ deficiency [2]. Approximately $85 \%$ of cases are type $1 \mathrm{HAE}$, which is characterized by reduced levels of circulating C1 INH [3,4]. The remaining $15 \%$ of cases are type 2 HAE, which is characterized by dysfunctional circulating $\mathrm{C} 1 \mathrm{INH}[3,4]$. A child will have a $50 \%$ chance of inheriting HAE if one parent has the disease; however, $25 \%$ of cases arise from de novo mutations [3]. Inherited

\footnotetext{
* Correspondence: bernstja@ucmail.uc.edu

+ Contributed equally

'University of Cincinnati, Department of Internal Medicine, Division of Immunology/Allergy Section, 231 Albert Sabin Way, Cincinnati, Ohio, USA Full list of author information is available at the end of the article
}

angioedema with normal $\mathrm{C} 1$ inhibitor levels has been described and is thought to be a separate disease resulting from a factor XII missense mutation that leads to bradykinin overproduction $[5,6]$.

Histamine mediated allergic inflammation is not involved in HAE [7]. Instead, HAE attacks result from contact, complement, and fibrinolytic plasma cascade activation, where $\mathrm{C} 1 \mathrm{INH}$ is a suicide inhibitor [2]. People with HAE have defective $\mathrm{C} 1 \mathrm{INH}$ synthesis with typical C1 INH levels that are 5\%-30\% of normal. ${ }^{2}$ Bradykinin is generated in large quantities via the contact pathway once $\mathrm{C} 1 \mathrm{INH}$ is depleted (Figure 1) [2]. Excess bradykinin production leads to acute HAE attacks as a result of increased vasodilatation, vascular permeability, and contraction of nonvascular smooth muscle [3].

HAE affects 1:50,000 people [8]. Fifty percent of patients will develop symptoms by age 10, although attacks have been reported in children as young as 2 years old [9]. Symptom frequency and severity may be extremely variable, even within families [4]. There may be no obvious trigger for attacks and no correlation between attack severity and subtype of disease. However, 


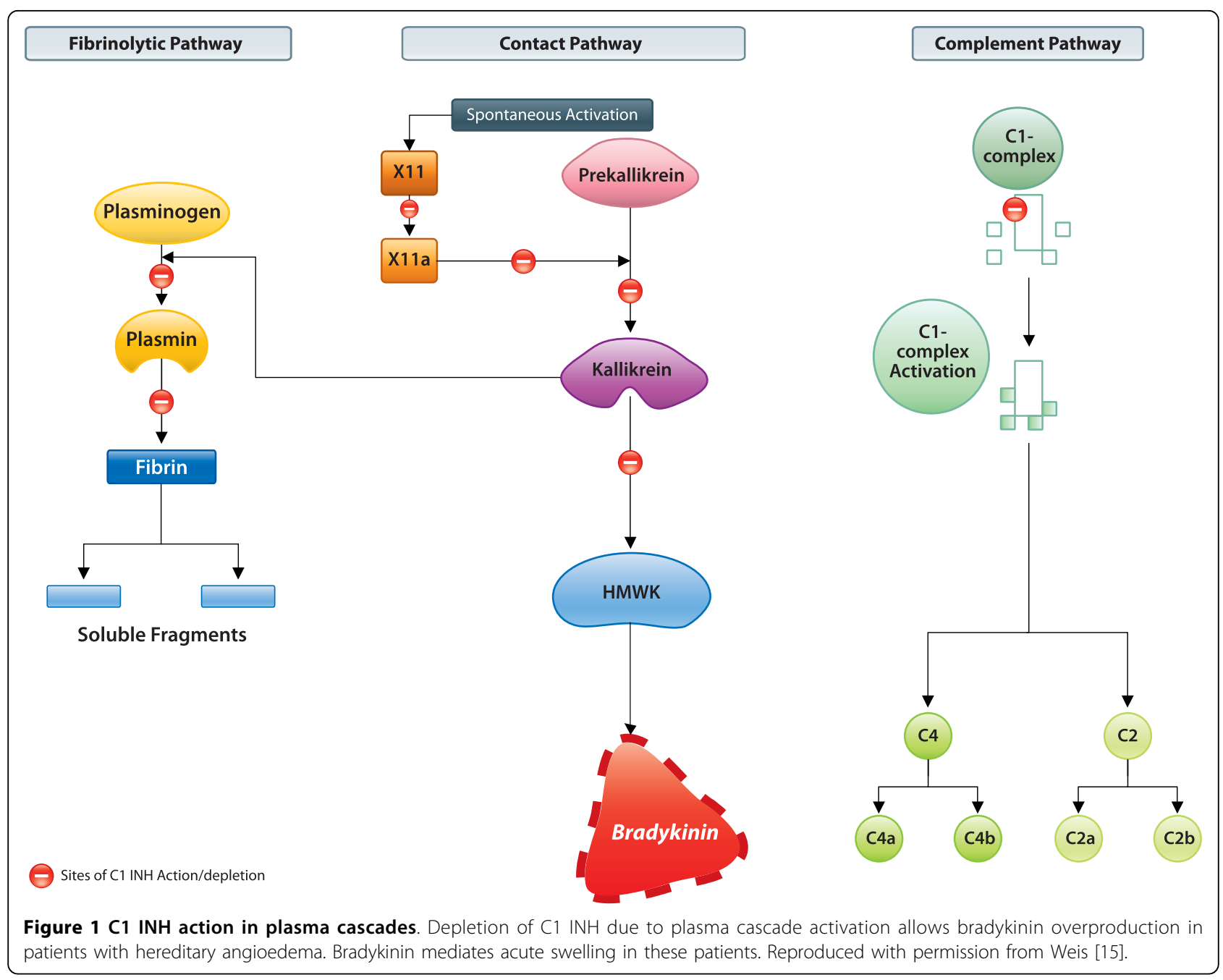

local trauma, stress, and hormonal fluctuations in women may be responsible for many attacks [10].

Despite the inherent risks of performing surgery on patients with $\mathrm{HAE}$, the cardiovascular surgery literature provides examples of uncomplicated surgery in patients who were methodically prophylaxed with different agents $[11,12]$. Appropriate choice of a prophylactic agent and its judicious use can help surgeons reduce peri-operative morbidity to patients, despite multiple sources of proteolytic cascade and complement activation known to occur with surgical trauma, and more specifically, with cardiac pump bypass surgeries [13,14].

Previous agents used for prophylactic treatment of HAE patients undergoing surgery include fresh frozen plasma, high-dose attenuated androgens, and anti-fibrinolytic agents. No agent is currently approved for shortterm procedural prophylaxis. However, newer agents are approved for long-term prophylaxis ( $\mathrm{C} 1$ esterase inhibitor [CINRYZE $\left.\left.{ }^{\mathrm{Tm}}\right]\right)$ and acute attacks (C1 esterase inhibitor $\left[\right.$ Berinert $\left.\mathrm{P}^{\circ}\right]$ and kallikrein inhibitor, ecallantide
[KALBITOR ${ }^{\circ}$ ]). Here we report a case of successful short-term prophylaxis using $\mathrm{C} 1 \mathrm{INH}$ in a 51-year-old man with HAE undergoing redo mitral valve reconstructive surgery.

\section{Case presentation}

A 51-year-old man with type $2 \mathrm{HAE}$, a history of acute respiratory failure, chronic airway obstruction, adhesive pericarditis, congestive heart failure, chronic pulmonary heart disease, and previous mitral valve annuplasty was scheduled for redo surgery six months after the initial surgical procedure due to severe mitral valve regurgitation. During the initial surgical procedure, the patient was successfully prophylaxed with $\mathrm{C} 1 \mathrm{INH}$ and his perioperative course was uneventful. Details of the initial surgery were previously published in abstract form [12].

The patient reported onset of HAE symptoms beginning at age 12. Previous attacks consisted of abdominal, facial, extremity, and painful genital swelling. He reported two previous episodes of severe laryngeal 
edema secondary to oral surgeries. The patient was controlled on long-term prophylaxis with the attenuated androgen, danazol $400 \mathrm{mg}$ daily, under the care of an allergist. However, even while on this medication, he reported breakthrough swelling including laryngeal edema. Historically, his $\mathrm{C} 1 \mathrm{INH}$ levels were normal, but the $\mathrm{C} 1 \mathrm{INH}$ was dysfunctional, and he had a persistently low $\mathrm{C} 4$ level - typical findings in type $2 \mathrm{HAE}$.

Two months after the initial mitral valve reconstruction and annuloplasty surgery, the patient presented to the emergency department in heart failure due to pericardial effusion. The patient's surgeon and allergist were consulted prior to any procedure. As a result, the patient was prophylaxed with $\mathrm{C} 1 \mathrm{INH} 1000$ units prior to pericardiocentesis, where one liter of pericardial fluid was removed. A transesophageal echocardiogram showed moderated-to-severe mitral valve regurgitation secondary to failure of previous repair. The procedure was tolerated without swelling.

The patient was scheduled for redo mitral valve repair six months later. Laboratory studies prior to surgery preparations were unremarkable except for chronic anemia. Cardiac catheterization was performed 48 hours prior to repeat mitral valve reconstruction. $\mathrm{C} 1 \mathrm{INH}$ 1000 units was administered six hours before cardiac catheterization. Since the patient was on danazol 400 mg daily, his functional $\mathrm{C} 1 \mathrm{INH}$ levels were within the normal range, but his $\mathrm{C} 4$ level remained low. $\mathrm{C} 1 \mathrm{INH}$ 1000 units was again administered intravenously twelve hours before repeat mitral valve reconstruction. During the redo surgery, the patient underwent sternotomy with lysis of extensive mediastinal adhesions, redo mitral valve repair with resection of chordae tendineae, and closure of dehisced prior leaflet closure; removal of annuloplasty band and insertion of 32 CardioMedics annuloplasty ring; and intraoperative 2-D esophageal echocardiogram for aortic ultrasound.

The surgery was uncomplicated without excessive blood loss. The patient experienced no postoperative complications associated with the surgery or HAE. He was extubated, the Swan-Ganz was discontinued, and danazol $400 \mathrm{mg}$ daily prophylaxis was resumed on postoperative day one. Chest tubes were removed on postoperative day two, and the patient was transferred to the regular nursing floor. He was discharged on postoperative day 4 and instructed to follow-up with the allergist caring for his HAE as an outpatient.

\section{Conclusions}

Three medications are available for acute treatment of HAE: Berinert- $\mathrm{P}^{\circ}$ (plasma-derived $\mathrm{C} 1$ esterase inhibitor, approved in the US and Europe), KALBITOR ${ }^{\circ}$ (ecallantide, a kallikrein inhibitor, approved only in the US currently), and Firazyr ${ }^{\circ}$ (icatibant, bradykinin $\beta 2$-receptor
Table 1 Consensus guideline C1 INH dosages for procedural prophylaxis

\begin{tabular}{ll}
\hline Patient weight & C1 INH dose \\
\hline$\leq 50 \mathrm{~kg}$ & 500 units \\
\hline$>50 \mathrm{~kg}$ to $\leq 100 \mathrm{~kg}$ & 1000 units \\
\hline $100 \mathrm{~kg}$ & 1500 units \\
\hline
\end{tabular}

Administer 1 hour before procedure. Have additional doses available if needed during and after surgery. $\mathrm{C} 1 \mathrm{INH}=\mathrm{C} 1$ esterase inhibitor.

inhibitor, approved only in Europe currently). Two medications are available for long-term prophylaxis: CINRYZE $^{\mathrm{ma}}$ (C1 esterase inhibitor [human], approved in the US) and the attenuated androgen, danazol (approved in the US and Europe). The newer medications target the underlying pathology of HAE and have less potential for long-term side effects than androgens. No medication is currently approved for procedural prophylaxis. However, consensus guidelines recommend the use of $\mathrm{C} 1 \mathrm{INH}$ (Table 1) and there are now many case reports of using C1 INH pre-operatively in Europe and the US $[8,12]$.

This case demonstrates that major surgery can be performed on HAE patients if care is closely coordinated. One week after surgery, this patient's long-term danazol prophylaxis dosage was reduced to $200 \mathrm{mg}$ once daily. With close management, this patient now experiences only a few breakthrough symptoms during normal activity, and he has needed procedural prophylaxis with $\mathrm{C} 1$ $\mathrm{INH}$ for a dental procedure only once since his mitral valve surgery. This case also demonstrates that typical long-term prophylactic doses of $\mathrm{C} 1 \mathrm{INH}$ may be sufficient for prophylaxis prior to major surgery. Prior to his initial mitral valve replacement, the patient received 2000 units of $\mathrm{C} 1 \mathrm{INH}$. However, after consulting an HAE expert, the doses for subsequent procedures were reduced to 1000 units with comparable results.

Procedural prophylaxis protocols should include a thorough patient history, coordinated efforts among medical specialties, family education, and use of an appropriate prophylactic medication. The successful use of a procedural prophylaxis protocol in this case will hopefully encourage the use of appropriate prophylaxis in patients with HAE who may be otherwise denied surgery.

\section{Consent}

Written informed consent was obtained from the patient for publication of this case report. A copy of the written consent is available for review by the Editor-in-Chief of this journal.

\section{Acknowledgements}

Clay Isbell and Innovative Strategic Communications Inc. assisted in the preparation of this manuscript and provided editorial services paid for by ViroPharma Incorporated. 


\section{Author details}

${ }^{1}$ University of Cincinnati, Department of Internal Medicine, Division of Immunology/Allergy Section, 231 Albert Sabin Way, Cincinnati, Ohio, USA. ${ }^{2}$ Innovation Center, Kettering Health Network, 3535 Southern Blvd, Kettering, Ohio, USA. ${ }^{3}$ Allergy and Asthma Centre of Dayton, 8039 Washington Drive, Suite 100, Centerville, Ohio, USA.

\section{Authors' contributions}

$J \mathrm{~B}, \mathrm{SC}$, and $\mathrm{AJB}$ contributed to the initial concept and design of the manuscript, provided the data presented, performed critical review of the medical concepts, and read and approved the final version.

\section{Competing interests}

The authors received honoraria for the development of this manuscript. SC has received research support from ViroPharma Incorporated. AB has received speaker fees from Merck, Genentech/Novartis, and GlaxoSmithKline.

Received: 5 October 2010 Accepted: 18 October 2010

Published: 18 October 2010

\section{References}

1. Frank MM: Hereditary angioedema: the clinical syndrome and its management in the United States. Immunol Allergy Clin North Am 2006, 26(4):653-668.

2. Agostoni A, Aygoren-Pursun E, Binkley KE, Blanch A, Bork K, Bouillet L, Bucher C, Castaldo AJ, Cicardi M, Davis AE, et al: Hereditary and acquired angioedema: problems and progress: proceedings of the third C1 esterase inhibitor deficiency workshop and beyond. J Allergy Clin Immunol 2004, 114(3 Suppl):S51-131.

3. Nzeako UC, Frigas E, Tremaine WJ: Hereditary angioedema: a broad review for clinicians. Arch Intern Med 2001, 161(20):2417-2429.

4. Gompels MM, Lock RJ, Abinun M, Bethune CA, Davies G, Grattan C, Fay AC, Longhurst $\mathrm{HJ}$, Morrison L, Price $\mathrm{A}$, et al: $\mathrm{C} 1$ inhibitor deficiency: consensus document. Clin Exp Immunol 2005, 139(3):379-394.

5. Bork K, Barnstedt SE, Koch P, Traupe H: Hereditary angioedema with normal C1-inhibitor activity in women. Lancet 2000, 356(9225):213-217.

6. Zuraw BL: Clinical practice. Hereditary angioedema. N Engl J Med 2008, 359(10):1027-1036.

7. Davis AE: Mechanism of angioedema in first complement component inhibitor deficiency. Immunol Allergy Clin North Am 2006, 26(4):633-651.

8. Bowen T, Cicardi M, Bork K, Zuraw B, Frank M, Ritchie B, Farkas H, Varga L, Zingale LC, Binkley $\mathrm{K}$, et al: Hereditary angiodema: a current state-of-theart review, VII: Canadian Hungarian 2007 International Consensus Algorithm for the Diagnosis, Therapy, and Management of Hereditary Angioedema. Ann Allergy Asthma Immunol 2008, 100(1 Suppl 2):S30-40.

9. Bork K, Meng G, Staubach P, Hardt J: Hereditary angioedema: new findings concerning symptoms, affected organs, and course. Am J Med 2006, 119(3):267-274

10. Frank MM, Gelfand JA, Atkinson JP: Hereditary angioedema: the clinical syndrome and its management. Ann Intern Med 1976, 84(5):580-593.

11. Lehmann A, Lang J, Boldt J, Saggau W: Successful off-pump coronary artery bypass graft surgery in a patient with hereditary angioedema. J Cardiothorac Vasc Anesth 2002, 16(4):473-476.

12. Codispote $C D$, Rezvani M, Bernstein JA: Successful use of $C 1$ inhibitor during mitral valve replacement surgery with cardiopulmonary bypass. Ann Allergy Asthma Immunol 2008, 101(2):220.

13. Segal H, Sheikh S, Kallis P, Cottam S, Beard C, Potter D, Townsend E, Bidstrup BP, Yacoub M, Hunt BJ: Complement activation during major surgery: the effect of extracorporeal circuits and high-dose aprotinin. J Cardiothorac Vasc Anesth 1998, 12(5):542-547.

14. Soulika AM, Khan MM, Hattori T, Bowen FW, Richardson BA, Hack CE, Sahu A, Edmunds LH Jr, Lambris JD: Inhibition of heparin/protamine complex-induced complement activation by Compstatin in baboons. Clin Immunol 2000, 96(3):212-221.

15. Weis M: Clinical review of hereditary angioedema: diagnosis and management. Postgrad Med 2009, 121(6):113-120.

doi:10.1186/1749-8090-5-86

Cite this article as: Bernstein et al: Successful C1 inhibitor short-term prophylaxis during redo mitral valve replacement in a patient with hereditary angioedema. Journal of Cardiothoracic Surgery 2010 5:86.

\section{Submit your next manuscript to BioMed Central and take full advantage of:}

- Convenient online submission

- Thorough peer review

- No space constraints or color figure charges

- Immediate publication on acceptance

- Inclusion in PubMed, CAS, Scopus and Google Scholar

- Research which is freely available for redistribution 